\title{
Study on the ecological wisdom of the grape drying room in Mazar village of Turpan from the perspective under the constraint of regional resources, China
}

\author{
Fuli Meng ${ }^{1,2}$, and $Y i \mathrm{He}^{1, *}$ \\ ${ }^{1}$ Huazhong University of Science \& Technology, Wuhan Hubei 430074, China \\ ${ }^{2}$ School of Literature and Art, Shihe-zi University, Shihe-zi832003, Xinjiang, China
}

\begin{abstract}
Productive grape-dry room in Turpan of Xinjiang is the core element of the spirit of the grape culture craftsman. Grape-drying house has 2 aspects of internal and external properties:(a)As productive building: which the process of using in regional resources about the practice of ecological agriculture; (b)As an oasis agricultural cultural heritage in Arid Areas:witnessing the history, culture and technology transmission and development of the ancient Silk Road in the Western is a living building sample, which has universal cultural and practical value in the current production and life, culture, etc.This paper is select studying of the traditional grape growing area of Mazar Village, which using the approach of interdisciplinary to cultural geography and ecology, and it is combed the characteristics of 4 aspects of ecological economic artistic and aesthetic of the Grape-drying House from the perspective of the Craftsman's Spirit. The artcle is analysised of 3 aspects from coping with climate resources, coordination of human land relations and building schem construction. The results show that: Concising 7 types of special regional environment to create unique ecological practice model (The upper layer is the Grape-drying room and the lower is the Living room;Building around the dwellings; Building in high altitude ventilation and shelter;Low technology and lower consumption ; The principle of appropriate balance of land using, etc. This study provides some reference for the later research.
\end{abstract}

\section{Introduction}

Under the background of Xinjiang's agricultural civilization, the grape drying house is the product of the joint role of the craftsman's wisdom and the nature and the humanities. It is a great significance to study the current green building in the arid area. The research results are mainly focused on the Micro-leve of the form, visual art and historical development of the architecture[1-4]. It is still insufficient to study the multi-layer property and multi-scale ecological wisdom of production and architectural heritage in the context of human settlements in ethnic minority areas.

\footnotetext{
*Corresponding author: 2188728992@qq.com
} 
The study area Shanshan oasis has the independence and typicality of the geographical unit and cultural unit. It has the advantageous geographical and resource conditions to cultivate the grape culture tourism town with national characteristics. The multi-dimensional study of the grape drying house, which is an important cultural landscape type and tourism resource, is particularly important. This paper selects the universal village of Mazar as the research object, through the case study of the typical grape growing area of Mazar village.

\section{Methodology}

\subsection{Study areas}

\subsubsection{Natural elements___ The formation of material base in the grape drying room}

The Turpan basin is located in the eastern part of Xinjiang. The mountain basins in the eastern Tianshan Mountains are surrounded by three hills. By aerial photographs, Turpan basin has a large number of alluvial fans, oasis plains and valley oasis basins, which provide good land resources for grape cultivation. The Shanshan oasis basin is located in the ashinterland of the Eurasian continent, which belongs to the continental warm temperate desert climate, with the characteristics of climate, dry rain, large evaporation, and large day and night temperature difference. Winter is cold, summer heat, the surface temperature is up to 70 80 degrees, the annual sunshine time is about $3000-3200 \mathrm{~h}[5]$. The above climate features provide a natural advantage and a comprehensive basis for the planting of grapes in Turpan oasis, quality and processing of grapes.

\subsubsection{Human elements - - The cultural foundation of the grape drying room}

Shanshan oasis is located in the ancient Silk Road cultural hub, at this intersection, cultural space advantages, provide social conditions richly endowed by nature and its frequent regional prosperity and sustainable interaction, but also for the processing and fruit grape planting in Turpan area to provide a communication and learning platform provides a humanistic environment in the Shanshan region prominent. The mazar village is one of the ancient village under the Shanshan County tuyugou township (See Figure 1), the unique humanity environment is one of the most important factors in the development of the typical grape culture landscape: Since ancient times, the region has a tradition of mulberry spinning, and multiple religions converge and change here, and the economy prosperity. There are historical cultural landscapes distributing on both sides of the valley of the Tuyugou gully: "Ding Gu Temple" is also called thousand -Buddha cave and the ancient Mazha group, to witness the cultural changes of the village. At the bottom of the valley, there is formationing an ancient road to form a flat natural oasis, which provides good land, water and human foundation for the planting of traditional grapes in the region. The village of Mazar preserves a large number of planting and production space for grapes, which protects the ecological environment of the oasis in this area. improves rural living environment, and creates a natural ecological law, to create the traditional settlements environment technology etc[6], has become a symbol of high identification of Grape Agricultural Cultural Landscape in Turpan. 


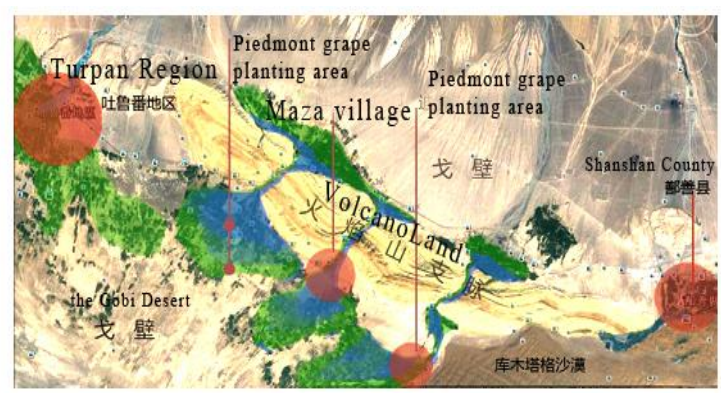

Fig. 1. Regional relation diagram of research objects.

\subsection{Data descriptions and pre-processing}

In this study, the traditional settlement of Turpan typical grape planting area was selected as the research sample, and the ArcGIS10.2 geographic information analysis platform was used to make a comprehensive analysis of the main driving factors affecting the construction of the grape drying room, such as the humanistic background, the natural conditions, the economic drive and so on, and summarized the ecological construction mode of the grape drying room.

\section{Results}

The cultural landscape characteristics of the grape drying room from the perspective of the ecological wisdom.

As a typical sample of the study of oasis agricultural cultural landscape, mazar village reflects the mappings of the craftsman's wisdom in the regional production architecture. The common characteristics of Turpan grape planting cultural landscape. As a core element of grape culture landscape with regional characteristics, grape room is discussed in terms of ecological dimension, economic dimension, art and aesthetics dimension etc.

\subsection{Ecological characteristics of the grape drying room}

The grape drying room is to cope with the dry and hot weather conditions in Xinjiang, and to improve the microclimate of the Human living environment in Oasis. Adapting to the shortage of water resources and arable land resources in Turpan oasis, selecting grape crops and building and producing airhouses as the important way of survival and ecology in this area, we summarize 2 aspects of ecological characteristics.

\subsubsection{Improving the ecological nature of the oasis environment}

The organic combination of grape drying room and houses, not only meet the grape drying function, but also improve the living environment, create a suitable living environment, grape dry room, Grape Garden, semi basement and other factors to help local residents to solve the Heat insulation, heat insulation, and sunscreen etc. Constructioning and using the grape drying room to follow the natural conservatism principle in a certain extent, to protect the fragile ecological environment of oasis, embodies the materialism follow the natural law of survival of the simple ecological view[7]. The climate conditions of drought and less rain provide the prerequisites for the construction of the grape drying room, which also provides an effective ecological model to adjust the dry and hot climate. 


\subsubsection{The ecology of construction materials}

Building materials in the use of recycled materials, the life cycle of the application in barn building material, the material itself ecological recycling characteristics, the local people respect the natural resources recycling principle, realize real resource sustainable.

\subsection{The economic characteristics of the grape drying room}

\subsubsection{The economic characteristics of the grape drying room are in the construction and Material}

The materialized form transformed by production technology - the economic characteristics of the grape drying room. (1) The economical of the grape drying room are in the construction and Material of obtain raw material locall. The local building materials taken from the foot of the dry earth by the people. As the Productive of earth buildings, yellow clay and ryegrass is the main material of adobe bricks, mix together, made of different sizes for different parts of the building brick, respectively. Simple pylons is arranged in the rafters inside the Drying room, soliding and fastening with branches, hooks, to hang the grapes. (2) The simple principles of the construction process. The grape drying room in mazar village follows this rule. The selection of the material is simple and the plasticity is high. Low cost, excellent heat absorption and heat dissipation, simple construction. Based on the construction material is simple, low cost, suitable for the development of local economy, to promote the use of large-scale.

\subsubsection{The economic characteristics of the development of the courtyard economy}

(1) As a traditional Grape courtyard Economy. The economy of the Grape Garden in mazar village has become an important part of the economic structure of grape planting in this area. In the field research of Mazar village, it is found that there are custom of planting mulberry grapes in traditional courtyard. Grape yard planting and processing meet the demand of self food, and the sale of external market is also one of the main sources of family income to solve livelihood problems. Grape trellis and grape drying room have become a necessary building for local families, as an important part of the function of the courtyard.

(2) The value of tourism resources as an oasis architectural cultural landscape. With the nineteen reports, the implementation of the revitalization of the rural strategy is proposed, and the regional characteristics of the oasis are excavated. It is one of the most important measures to solve the problem of rural poverty, economic development and social stability to cultivate and build a project of "one village, one product" and support the economic characteristics of Grape Garden[8]. In the new era, it gradually evolved into the grape cultural landscape resources with multiple values. In the face of the historical opportunity of the strategy of rural revitalization, the cultural value, economic value and ecological value of the courtyard in the public field of vision are reshaped.

\subsection{Artistic and aesthetic characteristics under the spirit of the craftsman}

The grape drying room, as the first productive building, has been expanded at many levels in the new era. Mazar village is the epitome of the typical oasis environment in Turpan oasis[9], which is adapted to the natural characteristics of the oasis environment.(See Figure 2). 


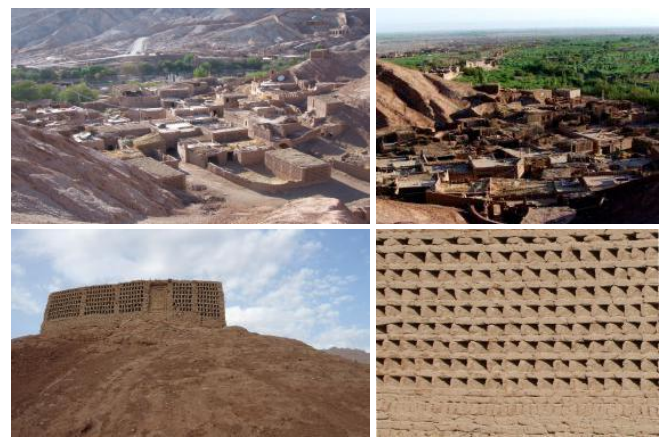

Fig. 2. Architectural and aesthetic features in the environment.

\section{Exploration: The ecological wisdom of the grape drying house under the endowment of regional resources}

The difference and uniqueness of the endowment of regional resources are the foundation of ecological wisdom which is formed with distinct regional differences and environmental corresponding[10]. The feedback of harmonious ecological wisdom maintains the local ecological balance and harmonizes the relationship between man and nature[11]. (1) The effective use of climatic resources, (2) Ecological adaptation of man-land relationship(Multiple types of site selection, convenient and economical travel range, the diversity of land use), which map man-land relationship, and solve the effective production and life model of livelihood and ecological problems. Oasis residents in the residential roof and hillside facilitate the ventilation place to build a grape room. The special construction mode integrates the local production and life style with the natural conditions of climate.

\subsection{Ecological wisdom of replying to climate characteristics}

The ingenious combination of the grape drying room and residence, natural and artificial ecological air drying system save the cost of building the room, convenient production, practical life, They create a "livable, suitable" oasis human settlement.

Through the author's reference to the relevant academic achievements, in the light of its own from 2016 to 2017 for Grape barn of on-site investigation in Tuyugou Township, 2 rules of climate adaptability are summed up by the author: (1) The terrain elevation is the main factor of the change of the microclimate of the Flaming Mountains, and it is also one of the important considerations for the construction of the site of the grape drying room. The results of this study are based on the analysis of Arc Gis10.0 geographic information software: The main range of the main elevation distribution in Mazha village and its periphery is $150 \mathrm{~m}$ $240 \mathrm{~m}$, and the number is 137 , accounting for $65.35 \%$ of the total; In the range of $240-310 \mathrm{~m}$, the number is 52 , accounting for $23.30 \%$, and the above $310 \mathrm{~m}$ above is less distributed here; In the relatively stable elevation, the grape drying room presents a cluster state, and the grape planting area and the distribution pattern of the living space are superimposed. (2)The grape drying room follows the ecological law of the suitability of the change of surface temperature. The summer and autumn surface temperature in the distribution area of the grape drying room in the southwest part of Tuyugou area is 37.2 56.80 degrees, the average temperature is 45.98 degrees, and the surface temperature is $48 \sim 51$ in the range of $48 \sim 51$. As a whole, the most suitable surface temperature of the air room is 49 50 degrees, and the best temperature of the raisin drying in Shannan area is 49 50 [12]. 


\subsection{Ecological wisdom based on the harmony of man-land relationship; and adjustment}

Study of the morphological characteristics of a time and space settlement from the perspective of man-land relationship, the aim is to "explore the relationship between buildings (groups) and the natural environment and the spatial relationship between buildings", by analyzing the value of this special spatial location, we can establish a basic mode of "maximize the use of resources and minimize the cost of human labor"[13]. Therefore, based on the "time constraint mechanism" of production and life, and the allocation principle of land resource level, we discuss the driving factors of the distribution and utilization of grape drying room, and promote the production and life cost savings and the scientific and efficient allocation of land resources[14]. Mazai village is a typical sample to deal with the relationship between production and living land, and embodies the pattern of high efficient distribution of land resources.

\subsubsection{The settlement level: the coupling relationship between the grape drying room and the grape planting land and the residence}

The main agricultural planting structure of mazai village is made up of grapes, cotton, melon and other crops with low water consumption and low operating cost. Among them, the planting area of grape accounted for $68.52 \%$ of the ploughable area. In the agricultural income proportion, the grape planting crops were in the dominant economic position. The annual output of grapes used for processing raisins accounts for $37 \%-45 \%$ of the total output[15], which is higher than the average level of $10 \%$ in Shanshan County. The planting area of Mazar village is relatively flat in the village area, which is conducive to the irrigation area. The middle part of the village is the core residential area, and the living and living land presents a dumbbell shape. Grape drying room is mainly distributed in the "Chuan fonts" river group houses two floors in the Gaogang zone along the hillside, with nearby areas, grape 3 spatial types (see Figure 3).

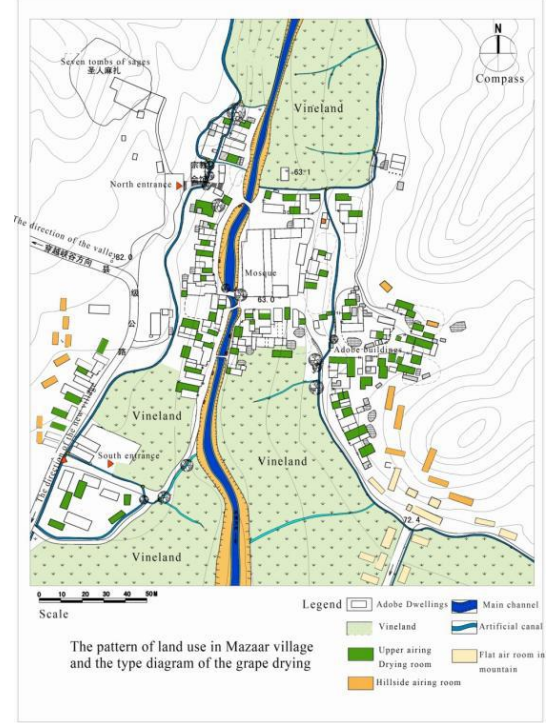

Fig. 3. Pattern of land use in mazaar village in Puyu gully and classification chart of grape drying room ${ }^{1}$.

${ }^{1}$ Figure 3 is drawn by Yuehong Li, a member of the research group, and adapted by the author, Fuli Meng 
The vertical characteristics of the settlement level in mazai village can be summarized as follows: in the field of land distribution and utilization, the grape drying room shows the vertical morphological characteristics of "low field of high field and upper air living". The distribution pattern of grape drying room in Mazar village is mainly composed of "living and production combination". The proportion of hillside potential type and flat front type is $30 \%$, and the two type is $12 \%$. The reason is that Mazar village is located on the top of the valley, which is impacted by the fan oasis. Considering the factors such as the topography, construction cost and technical conditions, it is relatively difficult to build a drying room on both sides along the slope. From the angle of ease of management to choose living and production space combination, this has become the main choice, it can be seen from the arcade barn, Tiaoyan barn. Based on the above analysis, Mazai village is not suitable for large-scale construction of airing room on the flat ground, so the vertical staggered roof air room is a typical local cultural landscape.

\subsubsection{The courtyard level: the ecological wisdom of the organic compound of "production \& life \& ecology"}

The organic compound of the living space and the airing space of "Upper air drying and lower living, ventilation and shelter", the vertical space of the airing room extends to the horizontal space.The compound residence and production space are of great significance for building the cool microclimate of residential space, saving the time cost of travel and realizing the transformation of multi-functional space: summer air house, autumn and winter storage, and intensive utilization of land resources.

Combination mechanism of "Upper air drying and lower living, ventilation and shelter": A layer of living space roof, the two layer is the grape drying room, and the thick and tall grape drying room plays the role of forming insulation space in summer, drying in autumn and keeping warm in winter. Home style grapes are mostly built at the top of the house to be ventilated. In general, residents of the building across the street or passageway upstairs upstairs, ventilation sun at the same time, saving land use effectively, increasing the shade area, reducing the courtyard and street temperature, the formation of small climate environment comfortable, not only meet the grape curing function and improving the living environment. Courtyard ecological model level: "level combination mode around the houses drying circle, attached ploughing and construction".

\subsection{3 "Create wisdom of low technology, high involvement, ecological cycle"}

Egional production space is used and inherited in a stable mode for a long time. The key factor is the richness of regional materials, the appropriateness of construction technology and the continuity of building subjects.

(1) Selection of materials of suit one's measures to local conditions, using material according to Low technology and high participation. These models can be presented in the construction and repair process of the grape drying room. From the aspects of site selection, climate adaptation and building interface processing, it can be concluded that the construction technology of grape room is much more complicated than that of residential buildings, and the production space plays a decisive role in the quality of family life. Therefore, the main body of Mazha village grape room is usually built on individual participation and collective participation. Though seemingly low-tech and co -construction activities play an important role in maintaining centripetal force.

(2) The unified coordination of 2 aspects of building space scale flexibly and masonry standards. (1) the flexibility of building space scale: Usually the airing room is usually the East and west side length, the north and south side wide, is advantageous to the ventilation, 
thus shortens the raisin drying time; The spatial scale of the construction depends on the planting area and family wishes of the grapes. (2) standardization of construction technical scale: For the specification of adobe bricks commonly used construction of grape drying room is long $30 \mathrm{~cm}$, wide $15 \mathrm{~cm}$, high $7 \mathrm{~cm}$, the specification and construction of other building material specifications are basically the same, its main purpose is to use adobe bricks, cycle in different construction cost saving, convenient construction and repair for masonry.

\section{Conclusion and Discussion}

\subsection{Conclusion}

The study excavates and expounds its ecological wisdom from 3 aspects: settlement level, courtyard pattern and construction technology. This is an important basic work to achieve local localization cultural construction and ecological construction. 3 categories of summing up in multi scale: (1) An ecological air - drying system combined with natural and artificial, (2)Harmony and adjustment of Man-land relationship, (3) Low technology, High involvement, ecological cycle,refined the ecological wisdom model of 7 small classes. This study considers that the traditional grape room under the background of traditional agriculture should be precisely protected and developed under the background of ecological civilization. We should regard the problems and values of dialectics as the dialectical development relationship, such as the recognition and respect of the relationship between man and land and the effective utilization of various resources. The traditional raw soil material has been largely replaced by brick of high energy consumption, low ecological; construction land has to be intensive, reducing the extremely fragile ecological zone of waste land; A new era of multi dimension value play to regional grape culture landscape resources, through the organic integration of traditional wisdom and the needs of the new era, and actively initiate long-term role in the minority villages develop specialty industries, promote the local characteristics of Rural Revitalization Strategy implementation, to achieve an affluent life, ecological environment and sustainable development.

\subsection{Discussion}

In this study, there is still room for further research on the development and conclusion of the research objects. The research samples are selected to have relevance, independence and typicality on the regional units. From the meso scale (traditional settlement level) to consider the representative, but because the selected unit (oasis area, courtyard settlement, etc.) the scale difference, studies the characteristics of homogeneous and heterogeneous research samples also showed different results, the influence of the mode of creating concise. Therefore, the universality and regularity of this research need further empirical analysis. We need more case studies to clarify the ecological wisdom of Turpan traditional grape drying house and adjust rules in the new era. This is also the focus of the follow-up research.

\section{Acknowledgments}

This study was supported by the National Social Science Foundation of China (14G126). In the process of writing, This paper could not be possible without the help of my Doctoral Supervisor Yi He as well as all the people from inside and outside Professor Weimin Que of city and the environment college of Peking University whose comments helped to improve 
the quality of a commanding height pointing, to express my sincere gratitude for them, and many thanks are due to the anonymous reviewers for their constructive comments and suggestions.

\section{References}

1. Zhang Yun. Analysis and Research on the elements of traditional humanities and natural native landscape in Turpan area . Beijing Forestry University. 2012,(06):51.

2. Lu Han, JiaYu. The characteristics of the traditional architecture of Xinjiang Uygur ethnic group, Journal of Architecture.1963, (01): 17-22.

3. Wang Yufen. Analysis of the artistic features of Turpan grape dry house architecture. Art education Research, 2012, (7) : 56.

4. Fuli Meng. Study on the spatial characteristics and types of Xinjiang oasis historical and cultural villages and their genetic mechanism [J], Journal of Guizhou National Research, 2018, (01):85.

5. Shan Jixiang. Into the world cultural landscape heritage M. Tianjin: Tianjin University press, 2010, (06): 55.

6. Lu Yinong, Wang Yuanxin. The grape drying room in Turpan - immortal earth architecture . Architecture and Culture, 2008, (02):82-83.

7. Li Chunjing. The arid climate environment of the local landscape design countermeasure research -- Taking Turpan mazarvillage and Yutian County old city for example, Xi'an University Of Architecture And Technology, 2011, (06): 65.

8. Yao Qian. Country culture is the soul of Rural Revitalization. Chinese culture newspaper, 2018, (02): (002).

9. Cai Wu Mei. Turpan area traditional residential space form of [D]. Shanghai. Shanghai Jiao Tong University School of media and design,.2011 (06):62.

10. Zhang Yingjie, Wang Wanjiang. The inheritance and protection of the architectural style of the grape dry room. Journal of Xi'an University Of Architecture And Technology (SOCIAL SCIENCE EDITION), 2015,34 (05):65-69.

11. Bai Baoli, Feng Kunsi. On the ethnic ecological ethics and the construction of harmonious society. Journal of Dalian University, 2007, (02):99-102.

12. Ma Jing. Study on the spatial pattern and dynamic changes of raisin processing air drying room in Shanshan oasis of Xinjiang [D]. Xinjiang Normal University, 2014, (06): 75.

13. Yue Bangrui, Wang Qingqing, Hou Quanhua. The perspective of man land relationship in Turpan mazarvillage oasis settlement pattern research of. Economic Geography,2011,31 (08),:1345-1350.

14. Li Yuehong. Research on the construction strategy of local settlement landscape under the constraints of water resources [D]. Xi'an University Of Architecture And Technology, 2011, (06): 51.

15. From 2010 to 2016 in Shanshan County, office of agricultural economic statistics report. 